\title{
RIGID MEDICAL THORACOSCOPY IN UNDIAGNOSED PLEURAL EFFUSION
}

Piyush Manoria, Prakash Joshi, Padmnabh Sharma, Shubham Chelavat, Gunjan Shrivastav, Pranay Bajpai, Sameer Maheshwari, R. K. Jha

1. Post Graduate Resident. Department of General Medicine, Shri Aurobindo institute of Medical Sciences and post graduate institute, Indore. Madhya Pradesh,

2. Associate Professor. Department of General Medicine, Shri Aurobindo institute of Medical Sciences and post graduate institute, Indore. Madhya Pradesh,

3. Post Graduate Resident. Department of General Medicine, Shri Aurobindo institute of Medical Sciences and post graduate institute, Indore. Madhya Pradesh,

4. Post Graduate Resident. Department of General Medicine, Shri Aurobindo institute of Medical Sciences and post graduate institute, Indore. Madhya Pradesh,

5. Post Graduate Resident. Department of General Medicine, Shri Aurobindo institute of Medical Sciences and post graduate institute, Indore. Madhya Pradesh,

6. Post Graduate Resident. Department of General Medicine, Shri Aurobindo institute of Medical Sciences and post graduate institute, Indore. Madhya Pradesh,

7. Post Graduate Resident. Department of General Medicine, Shri Aurobindo institute of Medical Sciences and post graduate institute, Indore. Madhya Pradesh,

8. Professor \& Head. Department of General Medicine, Shri Aurobindo institute of Medical Sciences and post graduate institute, Indore. Madhya Pradesh,

\section{CORRESPONDING AUTHOR:}

Dr. Piyush Manoria,

Post graduate Resident,

Department of Medicine,

Shri Aurobindo Institute of Medical Sciences and Post Graduate Institute. Indore (M.P.).

E-mail: manoria_piyush@yahoo.com

Ph: 00918085561132.

ABSTRACT: BACKGROUND: Pleural effusion is one of the common manifestations of tuberculosis and malignancy in our country. If it is not diagnosed early it can increase the morbidity and mortality. Pleural fluid analysis and blind pleural biopsy may not be helpful always .With this background we started our study to assess undiagnosed cases of pleural effusion by rigid medical thoracoscopy. AIM: As only few studies are published regarding the use of rigid medical thoracoscopy in the evaluation of undiagnosed pleural effusion, our present study aims to assess its significance in it. MATERIAL AND METHOD: In our study 22 cases were selected who came to our OPD with undiagnosed pleural effusion from January 2010 to January 2011 including both sexes and different age groups. Rigid medical Thoracoscopy were done in all of them. RESULTS: Out of 22 cases, 16 were diagnosed as malignant, 3 as tubercular, 1 as chronic inflammation, 1 as non specific and in 1 case procedure was not successful. CONCLUSION: With this study we found that rigid medical Thoracoscopy is an efficient procedure for diagnosing undiagnosed pleural effusion.

KEY WORDS: Thoracoscopy, Tuberculosis, Malignant Pleural Effusion, VATS.

INTRODUCTION: The etiology of pleural effusion is mostly established by pleural fluid examination for biochemistry, microbiology, cytology and ADA levels. If it is uncertain blind pleural biopsy is usually done, but even after that $20-25 \%$ of cases remain undiagnosed. (1) Medical Thoracoscopy is the best suitable answer for all these cases. With Thoracoscopy only 
less than $10 \%$ of cases remain undiagnosed. Medical Thoracoscopy is a simple form ofVATS which is done under conscious sedation through a single port by Physician. This study aims to share our experiences with Rigid Medical Thoracoscopy in cases of undiagnosed pleural effusion.

MATERIAL AND METHODS: We took patients attending the OPD with undiagnosed pleural effusion; following were inclusion and exclusion criteria.

INCLUSION CRITERIA: Patients with undiagnosed exudative pleural effusion with

A) Low ADA $(<40)$ with cytology negative or suspicious but inconclusive.

B) High ADA (>40) on ATT since at least 3 months with no improvement. EXCLUSION CRITERIA:

A) Patients who are very dyspnoeic.

B) Bleeding Diathesis.

C) Unstable CVS status.

D) Inadequate pleural fluid.

E) Lack of pleural space due to adhesions.

Medical Thoracoscopy was performed by placing the patient in lateral decubitus position with arms placed over the head. Site of entry was marked under USG guidance in midaxillary line. It was done under conscious sedation with midazolam and fentanyl. Site was infiltrated with LA (2\% Xylocaine). Then as for chest tube placement, small incision was made. A trocar was inserted after dissecting the incision. Pleural fluid was removed and the lung was allowed to collapse with the introduction of air. A rigid Thoracoscope $(10 \mathrm{~mm})$ was inserted into pleural cavity through the trocar and connected to a video camera. Pleural cavity was thoroughly examined and biopsies were taken from the diseased pleura under direct vision. Talc was insufflated (4gm) if pleural surface was found to be extensively infiltrated or patient was a follow up case of malignancy and visible lung expansion is seen. At the end of procedure ICD was inserted and connected to ICD bag which was subsequently removed in next 2-3 days.

RESULTS: Rigid Thoracoscopy was done in 22 patients during January 2010-January 2011 in undiagnosed pleural effusion of which 9 were males and 13 were females. Mean age was 52 years. Procedure was unsuccessful in 1 patient as we were unable to create an adequate pleural space. Pathological Diagnosis was Malignancy in 16 patients, out of which 15 had Adenocarcinoma and 1 had Mesothelioma. Out of these 16 patients 12 were on ATT. Tuberculosis was diagnosed in 3patients. Out of these 2 were already on ATT but not improving. Other diagnosis was Chronic Inflammation in 1 and nonspecific in 1patient. Thoracoscopic findings which were seen were nodules, infiltrations and adhesions. Talc insufflation was done in 11 patients. No complications were noted in either case.

DISCUSSION: Medical Thoracoscopy is the best suitable answer for undiagnosed exudative pleural effusion after initial pleural fluid analysis. Usually only two diagnoses are established with thoracoscopy i.e. Malignancy and Tuberculosis.

Thoracoscopy was first introduced by S.Gordon in 1866 who did it by abinocular instrument and later in 1910 by Hans Jacobaeus, a Swedish internist for breakdown of adhesions and creating artificial pneumothorax for treatment of tuberculosis. $(2,3)$ With the 
advent of Streptomycin in 1945its use declined. Now with the recent advances in endoscopic techniques it has again come in picture in last 15-20 years.

Rigid Thoracoscopy may be a better option than flexible or semi rigid as sample size is larger and visibility is better which increases its yield, although training required maybe a little more. ACCP recommends that the trainee should perform at least 20 procedures under supervised settings to establish basic competency.(4)

There are 2 techniques of doing it, single puncture and double puncture. In single puncture technique, Thoracoscope and all other instruments like biopsy forceps and suction catheter are inserted through a single port. In double puncture technique one port is for thoracoscope and second is for other instruments. Single port technique is a simpler one and is most commonly used.

Thoracoscopy will establish diagnosis of malignancy in approximately $90 \%$ of cases.(5,6).Pleural fluid cytology is positive for malignancy in $62 \%$ of cases.(7) Yield of cytology is less as it depends on the type of tumor (more positive in adenocarcinoma than others), quantity of specimen, cytologist and tumor burden.

Tubercular pleural effusion is usually diagnosed by pleural fluid ADA levels as it has a high sensitivity and specificity of93 \%.(8) Though some cases, like pleural fluid with high ADA levels but not responding to ATT or pleural effusion with low ADA but with high clinical suspicion require Thoracoscopy. The diagnostic yield of Medical Thoracoscopy is almost 100\% in tubercular effusions as multiple biopsies are taken under direct vision and culture of bacilli can be done. $(9,10,11,12)$

Medical Thoracoscopy if done properly is a safe procedure. Mortality rates of less than $0.1 \%$ have been reported. $(13,14)$ Usual complications are intrapleural bleeding, prolonged air leak and empyema.

For diagnostic purposes, Medical Thoracoscopy is as efficient as VATS. The difference between the two is that VATS is done in an intubated patient, under GA, by a surgeon, mostly therapeutic and is expensive; while medical Thoracoscopy is done in a spontaneously breathing patient, under LA and conscious sedation, by a physician, mostly diagnostic and is less expensive.

CONCLUSION: Medical Thoracoscopy is very safe, very efficient and less expensive investigation in aforementioned conditions. We have an excellent experience with it in diagnosing the cause of pleural effusion. It may be a better option than flexible or semi rigid thoracoscopy. Due to its higher yield the future of it is very bright.

\section{REFERENCES:}

1. Lee P, Colt HG: Rigid and semi rigid pleuroscopy: the future is bright. Respirology 2005; 10: 418-25.

2. JacobaeusHC: UberdieMoglichkeit, diezystoskopiebiedie, Untersuchungsseroser Hohlungenanzuwenden. Munch Med. Wochenschr 1910; 57 :2090-92.

3. Jacobaeus HC: The cauterization of adhesions in artificial pneumothorax therapy of tuberculosis. Am Rev Tuberc 1922; 6: 871.

4. Ernst A, Silvestri GA, John Stone D. American College of Chest Physicians. Interventional pulmonary procedures: guidelines from American College of Chest Physician. Chest 2003; 123:1693-1717. 
5. Hucker J, Bhatnagar NK, Al Jilaihawi AN et al. Thoracoscopy in the diagnosis and management of recurrent pleural effusion. AmThorac Surgery 1991: 52: 1145-1147.

6. Menzies R, Charbonneau M. Thoracoscopy for the diagnosis of pleural disease. Ann Inter Med 1991; 114: 271-276.

7. Lodden Kemper R. Thoracoscopy: state of the art. EurResir J 1988; 213-21.

8. Greeco S, Giardi E, MasciangeloR etal. Adenosine deaminase and interferon gamma measurement for the diagnosois of tubercular pleurisy: a meta analysis .Int J Tuberc Lung Dis 2003; 7: 777-786.

9. Lodden Kemper R, Grosser H, Mai J etal: Diagnostik dis tuber Pleuraergusses. PraxKlinPnemol 1983;37: 1153 -1156.

10. Gopi A, Madhavan SM, Sharma SK, Sahn SA. Diagnosis and treatment of tuberculous pleural effusion in 2006. Chest 2007; 13: 880-9.

11. Aggarwal AN, Gupta D, Jindal SK. Diaagnosis of tuberculous pleural effusion. Indian Journal of Chest Disease and Allied Sciences.1999; 41: 89-100.

12. Dia Con AH, Van de Wal BW, Wyser C, Smedeme JP, Benzuidenhout J, Bollinger CT, etal. Diagnostic tools in tuberculous pleurisy: a direct comparative study. EurRespir J 2003; 22: 589-91.

13. Viskum K, Enk B: Complications of thoracoscopy. Poumon Coeur 1981; 37: 25-28.

14. Boutin C, Viallat JR, Cargnino P et al : La thoracoscopie en 1980: Revue generale . Pouman Coeur 37: 11-19. 